\title{
SOBRE LITERATURA, FILOSOFIA E O CÔMICO \\ ENTREVISTA COM JACQUELINE RAMOS
}

\begin{abstract}
Leinimar Alves Pires é doutoranda em Literatura, Cultura e Contemporaneidade na Pontifícia Universidade Católica do Rio de Janeiro.

E-mail: leinimar@hotmail.com
\end{abstract}

Jacqueline Ramos é Doutora em Teoria Literária pela Universidade de São Paulo e, atualmente, Professora Adjunta na Universidade Federal de Sergipe. A pesquisadora faz parte do Grupo de Estudos em Filosofia e Literatura - GeFeLit (http://www.gefelit.net) - , formado por diversos professores e pesquisadores de ambos os campos de saber e de variadas Universidades. Os mesmos organizam a revista $A$ Palo Seco, Colóquios e Seminários e, em breve, iniciarão um curso de especialização na UFS, sempre se preocupando em especular e discutir a relação entre filosofia e literatura.

No mês de outubro do ano de 2010 tive a oportunidade de participar do "II Colóquio Filosofia e Literatura: fronteiras", realizado na cidade de São Cristovão, Sergipe, e de conhecer o trabalho de Jacqueline Ramos a respeito da presença e do papel do cômico na literatura de João Guimarães Rosa, e toda sua problemática filosófica.

A intelectual possui diversos artigos sobre o tema, desenvolve um projeto de pesquisa sobre o cômico na literatura brasileira e lançou o livro Risada e meia: comicidade em Tutaméia (Editora Annablume, São Paulo) no ano de 2009, resultado de sua tese de Doutorado defendida na USP em 2007.

1) Como surgiu a ideia de fundar o Grupo de Estudos em Filosofia e Literatura, o GeFeLit?

$\mathrm{O}$ GeFeLit surgiu de encontros informais de alguns professores, encontros que invariavelmente acabavam em calorosas discussões sobre literatura, filosofia, linguagem... Todos nós estávamos vinculados à universidade federal, desenvolvendo trabalhos de pesquisa, e percebemos que poderíamos produzir em conjunto, aproveitando melhor esse encontro, digamos, espontâneo entre professores de filosofia e literatura. Assim surgiu a idéia do GeFeLit. Mas transformar o que se constitui como encontro informal e criativo em pesquisa acadêmica sistemática nos exigiu muitas horas de debate até nos propormos um primeiro "exercício acadêmico". Aproveitando, naquele ano de 2008, a dupla efeméride de nascimento de Rosa e o de morte de Machado de Assis, promovemos nosso I Colóquio, que propôs a seus participantes a leitura dos contos homônimos de Machado e Rosa, "O espelho". Nove professores participaram e foram montadas três mesas, uma para as leituras do conto de Rosa, outra para as leituras do conto de Machado e a terceira para aqueles que promoveram uma 
comparação entre as narrativas. Foi um encontro muito instigante para o grupo que, motivado pelos resultados, fundou sua revista, A palo seco, publicando em seu primeiro número os textos desse Colóquio. Outro desdobramento foi a meta traçada para o ano subsequente (2009), o I Seminário de Pesquisa em que mensalmente discutimos os fundamentos e as perspectivas desse encontro interdisciplinar entre filosofia e literatura. Em 2010, você sabe, organizamos nosso II Colóquio, abrindo para participações externas, procurando aglutinar os interessados e conhecer outros trabalhos e outras perspectivas do encontro entre filosofia e literatura.

\section{2) Em que sentido você considera que o grupo de pesquisas contribui para as disciplinas e os estudiosos de Filosofia e Literatura?}

Creio que nossa contribuição é a de explorar as possibilidades dessa abordagem interdisciplinar e dar a ver o quanto filosofia e literatura se confundem em determinados momentos. O grupo, nestes primeiros anos de sondagem, tem explorado os pontos de contato entre as áreas, seja ele histórico, temático, procedimental. Temos então, por um lado, o resgate dessa relação entre as áreas e por outro a investigação metodológica, ou seja, como e por que trabalhar a/na interdisciplinaridade?

As relações entre filosofia e literatura são históricas, suas fronteiras são permeáveis... O mito da caverna e o mito da reminiscência, p. ex., são narrativas de que Platão lança mão em seus textos filosóficos (a propósito, a forma de diálogo já o aproxima do gênero dramático). $\mathrm{O}$ idealismo romântico talvez tenha sido o momento de maior indistinção entre poetas e filósofos, veja os irmãos Schlegel que produziram literatura, crítica e filosofia; Schelling, Hegel e Hölderlin foram amigos e mantiveram relações com Goethe, Tieck, Novalis... Poetas filósofos ou filósofos poetas... Nietszche precisou da linguagem literária para sua filosofia; Sartre escreveu seus romances; Wittegenstein também transita para os "jogos de linguagem"... E há o outro lado da moeda, quando é a literatura que promove a problematização da realidade: a literatura fantástica do século XIX já discutia questões que seriam mais tarde objeto de estudo da psicanálise. Aliás, Freud trava um franco diálogo com a literatura, podemos lembrar do nome daquele complexo, o de Édipo, ou de sua leitura de "O homem de areia" de Hoffman no desenvolvimento de seu conceito de estranhamento.

Sob o ponto de vista do crítico há momentos em que se consegue delinear bem as áreas, elas não se confundem: ora a filosofia oferece instrumental teórico para a entrada analítica no texto literário; ora nos ocupamos da intertextualidade que o texto literário promove com as ideias filosóficas; há os que se ocupam do tema da literatura nos textos filosóficos, e aqui entramos no terreno dos estudos literários, da estética, da natureza e função da arte que pertenceu ao âmbito da filosofia até o advento da linguística no século XX. Até aqui, o leque de possibilidades investigativas é imenso.

Há outro desafio, entretanto, que é enfrentar a "fronteira": o texto de Nietszche é tão literário quanto o de Rosa filosófico! Empenhadas no conhecer e dizer o mundo, filosofia e literatura enfrentam o mesmo problema: o da linguagem. Nunes alerta que a 
filosofia deu primazia ao enunciado e que deve aprender com a literatura os problemas da enunciação: a voz que fala e se inscreve no texto, a relativização da verdade, a consideração da perspectiva pela qual os objetos do mundo são representados. O que talvez explique o trânsito de tantos filósofos para o texto literário. A literatura permite forjar uma perspectiva e dar a ver uma determinada visão. A perspectiva do suposto marido traído em Dom Casmurro de Machado nos revela muito do modo como uma mente ciumenta se relaciona com a realidade. Ou seja, para além da estória de Bentinho, Capitu e Escobar, a obra coloca em debate o problema da percepção da realidade.

Este parece ser o ponto nodal entre as áreas: a linguagem. O título que Nunes dá a um de seus artigos "filosofia e literatura: uma transa" é muito expressivo, pois revela o envolvimento corpóreo e passional entre as áreas, isto é, o denominador comum da linguagem e os problemas da representação e do conhecimento da realidade.

\section{3) Quais características da obra de Guimarães Rosa a levou a elegê-lo como corpus de investigação literário-filosófica?}

Você disse bem, foi o Guimarães que me levou à filosofia. Todos aqueles que se debruçam sobre a obra de Rosa percebem o intenso debate que ele trava com a filosofia. Acho que posso dizer que já há uma tradição de estudos que se ocupam desse diálogo, como o de Suzi Sperber que mostra a correlação entre a organização das estórias de Corpo de baile com o sistema cósmico descrito no Timós e resgatado por Plotino; os estudos críticos de nosso saudoso Benedito Nunes, em que mostra, por exemplo, a retomada o eros platônico em algumas narrativas rosianas. Não podemos deixar de lembrar também do trabalho de fôlego de Francis Utéza que procura mostrar como Rosa condensa a tradição ocidental e oriental em seu debate metafísico em Grande sertão veredas; Heloisa Vilhena de Araujo promove um verdadeiro mapeamento das fontes e referências filosóficas de Rosa; Suzi Sperber também se ocupa do debate que Rosa promove com a filosofia... Estou citando de memória, sei que a fortuna crítica de Rosa vem se avolumando e que ela tem também explorado esse veio filosófico da obra. Aliás, é tarefa árdua ocupar-se desse debate filosófico dada a densa erudição do autor... Se vale uma confissão, eu sempre fugi desse diálogo! Apesar de instigada pela obra, a ausência de uma boa formação em filosofia foi a causa de minha esquiva. E, foi ainda fugindo desse diálogo, que me dediquei ao problema da comicidade na última obra de Guimarães Rosa, Tutaméia.

Ironia do destino! Quando comecei a analisar o primeiro prefácio da obra, dedicado ao debate sobre a natureza, função e formas da comicidade, me dei conta da exegese do problema que Rosa levava a cabo! Em citações diretas ou indiretas estão lá Aristóteles, Platão, Bergson, Freud, Shopenhauer, Kant, Nieszche etc. Nesse momento, percebi igualmente que a maior parte das fontes teóricas sobre o cômico são fornecidas pela filosofia e estão ali referidas, retomadas ou refutadas ou desdobradas ou corrigidas... foi assim que não pude mais fugir! E foi assim, pelo viés cômico, que Rosa me levou à filosofia - devo isso a ele! Aliás, se vale a provocação, o cômico, segundo 
Tutaméia, "não é rasa coisa ordinária", é instrumento para transcender os limites do pensamento sério, só ele é capaz de oferecer "o leite que a vaca não prometeu"! Os "mágicos novos sistemas de pensamento" promovidos pela comicidade estão implicados nas relações entre linguagem e conhecimento.

Tutaméia é emoldurada por epígrafes de Schopenhauer; Corpo de baile, por epígrafes de Plotino. Para um autor tão virtuose como é Rosa, não podemos deixar de notar a provocação, sua arte narrativa é também experimentação filosófica. Em Corpo de baile as personagens vivem a possibilidade essencialista, veja o encontro amoroso de Lélio e Lina, a comunhão de Pedro Orósio com o todo da natureza e da cultura. Em Tutaméia a perspectiva é radicalmente oposta, as personagens vivem segundo uma interpretação equivocada da realidade, "Barra da Vaca" é exemplar. Daí a perspectiva cômica na obra: ela é capaz de revelar esse estatuto humano, nosso engano, nossa condição ridícula em acreditar em explicações verossímeis do real. O que chamamos de realidade, é construção de linguagem pautada pelo desejo... Lembra de "Desenredo"? A diversidade de perspectivas nessas obras parece indicar que a literatura é também tomada por Rosa enquanto espaço de experimentação de ideias filosóficas. Se assim é, teríamos em obras como Corpo de baile e Grande sertão: veredas menos uma defesa do metafísico que o debate sobre a possibilidade metafísica (daí talvez a diversidade de fontes que condensa em sua obra).

\section{4) Qual é a programação do grupo para o ano de 2011?}

Como o GeFeLit é composto de professores de departamentos, campi e universidades diferentes, dificultando os encontros mais amiudados, temos nos organizado em torno de uma agenda de atividades, como foi o I Colóquio, o I Seminário, o II Colóquio. Neste ano de 2011, estivemos envolvidos em nosso projeto de especialização que acaba de ser aprovado nas instâncias competentes da UFS. A seleção dos candidatos deve ocorrer em julho para início em agosto. Nossa especialização em filosofia e literatura pretende oferecer por meio de um grupo de disciplinas, digamos, monográficas, um painel das possibilidades investigativas e das relações entre as áreas. O curso terá duração de três semestres, sendo que o último é reservado ao desenvolvimento de monografias individuais e orientadas, inaugurando uma produção mais sistemática do grupo. Nesse sentido, eu diria que a especialização é um momento de consolidação de nossa abordagem de pesquisa. Além disso, para os discentes é uma oportunidade de desenvolvimento de pesquisa e de continuidade em sua formação acadêmica. Ainda, por sua natureza, o curso também se abre para o estudo da abordagem interdisciplinar, tão apregoada nas orientações curriculares nacionais e de difícil penetração haja vista o histórico da tradicional compartimentalização das áreas no ensino.

Bem, afora a especialização, que seria a atividade que congrega o grupo como um todo, cada pesquisador desenvolve sua pesquisa específica, envolvendo, na maioria 
dos casos, alunos da graduação seja em grupos de estudos, seja através do programa de iniciação científica, programa de iniciação à extensão etc. 